\title{
Tuning Adsorption Capacity by Alkoxy \\ Groups: A Study on Acetic Acid Adsorption on \\ UiO-66 Analogues from Aqueous Solution
}

\section{Supporting Information}

Chuan Yu, Hongxu Liu, Jiafei Lyu, Zixing Xiao, Peng Bai, Xianghai Guo*

Department of Pharmaceutical Engineering, School of Chemical Engineering and Technology, Tianjin University, Tianjin 300350, P. R. China

Key Laboratory of Systems Bioengineering (Ministry of Education), Tianjin

University, Tianjin, 300072, P. R. China

*Corresponding author.Email: Guoxh@tju.edu.cn 


\section{Contents}

Section S $1{ }^{1} \mathrm{H}$ NMR Spectra of five linkers

Section S2 Characterized results of the adsorbents

Section S3 Textual properties of five UiO-66 samples

Section S4 Simulation of acetic acid adsorption on UiO-66-3

Section S5 Kinetic curves of acetic acid adsorption

Section S6 The Van't Hoff plot 
Section S1. ${ }^{1} \mathrm{H}$ NMR Spectra of five materials

2-methoxyterephthalic acid: $\delta$ 7.72-7.70(d, 2H, Ar-H), 7.60-7.57(d, 1H, Ar-H),

$3.90\left(\mathrm{~s}, 3 \mathrm{H}, \mathrm{OCH}_{3}\right) \mathrm{ppm}$

2-ethoxy terephthalic acid: $\quad \delta$ 7.72-7.70(d, 2H, Ar-H), 7.60-7.57(d, 1H, Ar-H), 4.20-

4.15(q, 2H, $\left.\mathrm{OCH}_{2}\right), 1.39-1.35\left(\mathrm{t}, 3 \mathrm{H}, \mathrm{CH}_{3}\right) \mathrm{ppm}$

2-n-propoxy terephthalic acid: $\delta$ 7.72-7.70(d, 2H, Ar-H), 7.60-7.57(d, 1H, Ar-H),

4.06-4.02(t, 3H, $\left.\mathrm{OCH}_{3}\right), 1.78-1.68\left(\mathrm{~m}, 2 \mathrm{H}, \mathrm{CH}_{2}\right), 1.01-0.97\left(\mathrm{t}, 3 \mathrm{H}, \mathrm{CH}_{3}\right) \mathrm{ppm}$

2-n-butoxy terephthalic acid: $\quad$ 7.72-7.70(d, 2H, Ar-H), 7.60-7.57(d, 1H, Ar-H),

4.10-4.07(t, 2H, $\left.\mathrm{OCH}_{2}\right), 1.74-1.67\left(\mathrm{~m}, 2 \mathrm{H}, \mathrm{CH}_{2}\right), 1.49-1.42\left(\mathrm{~m}, 2 \mathrm{H}, \mathrm{CH}_{2}\right), 0.95-0.91(\mathrm{t}$, $\left.3 \mathrm{H}, \mathrm{CH}_{3}\right) \mathrm{ppm}$

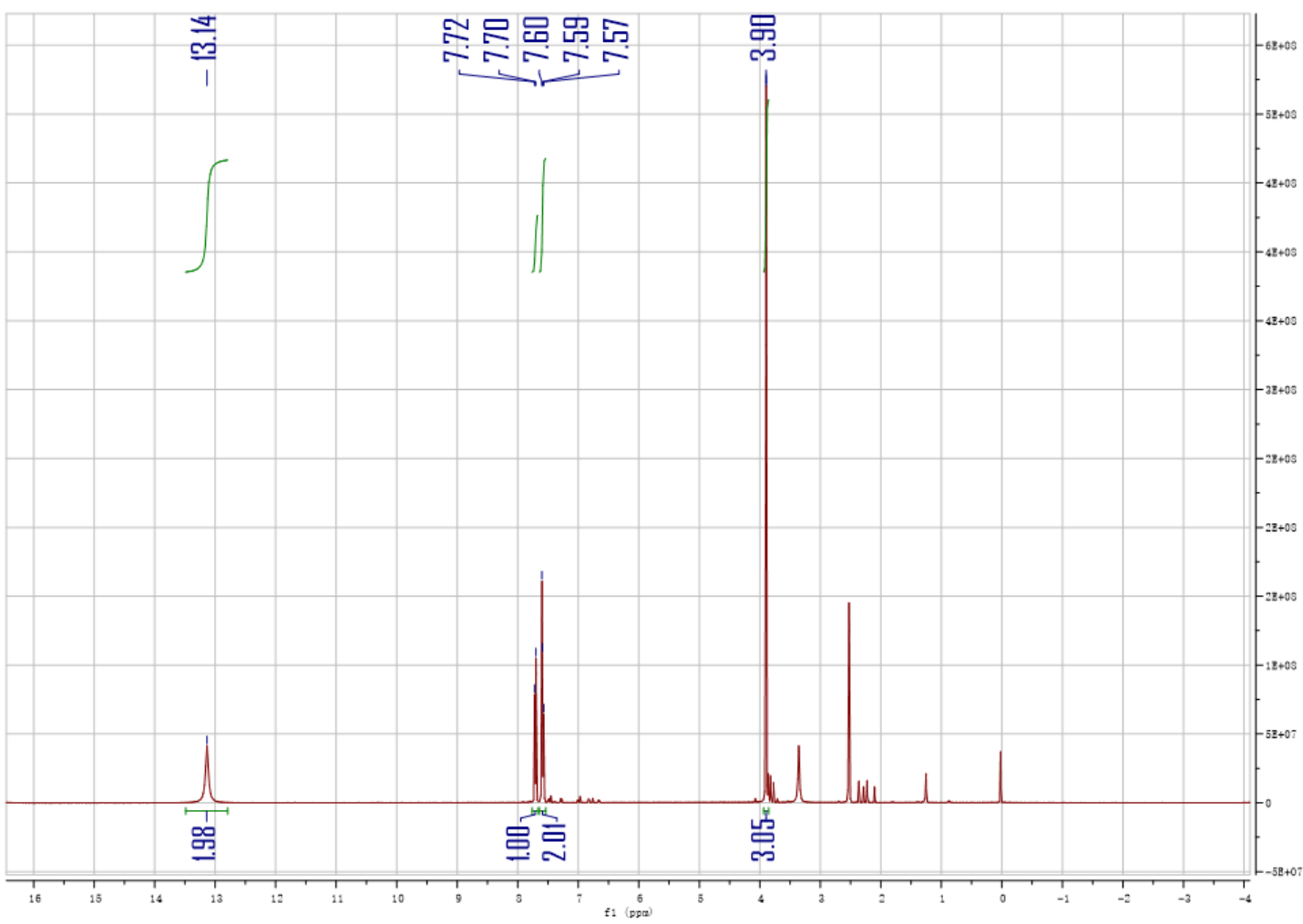

Figure S1 ${ }^{1} \mathrm{H}$ NMR(400MHz, DMSO) spectra of the linker of UiO-66-1 


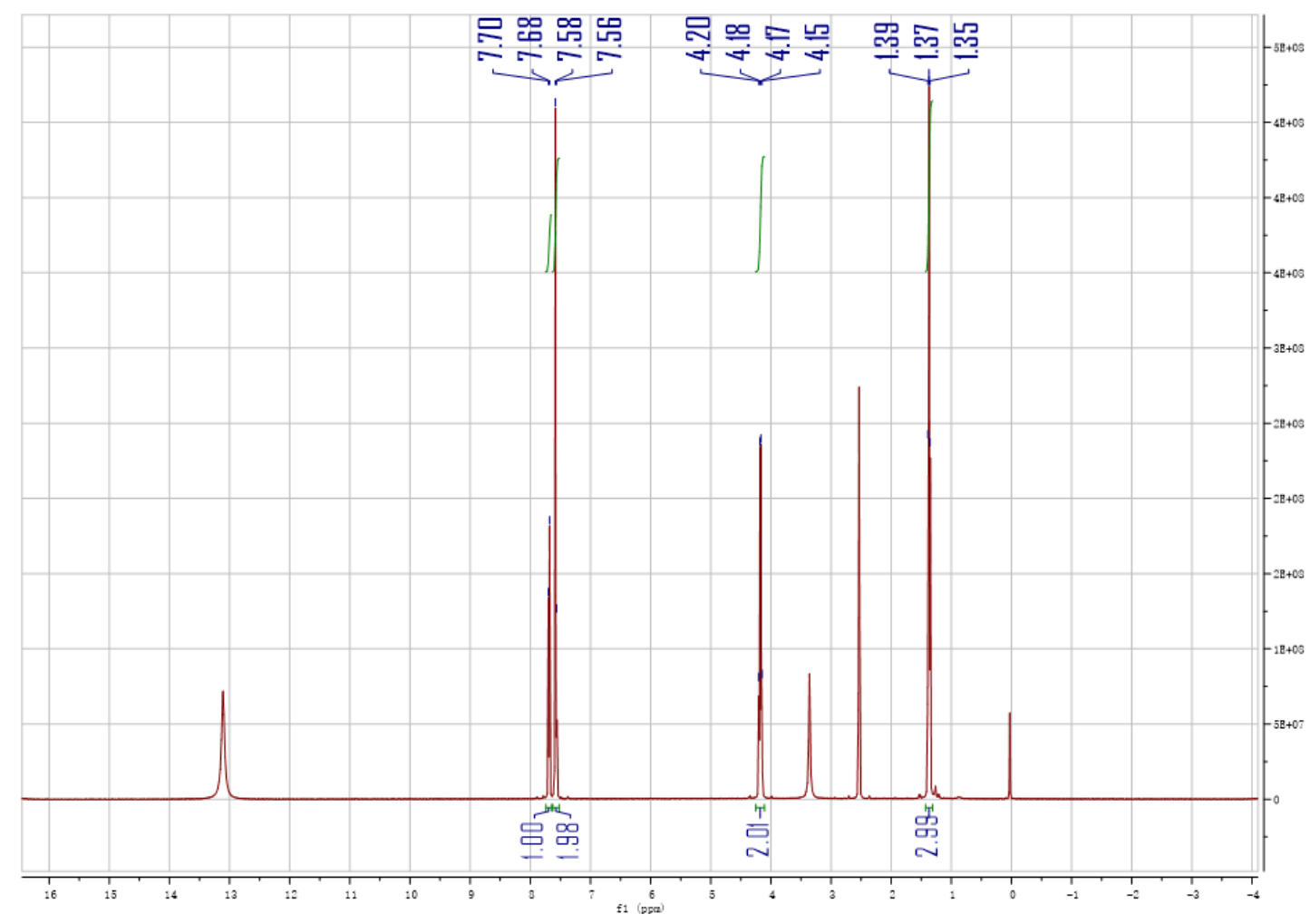

Figure S2 ${ }^{1} \mathrm{H}$ NMR(400MHz, DMSO) spectra of the linker of UiO-66-2

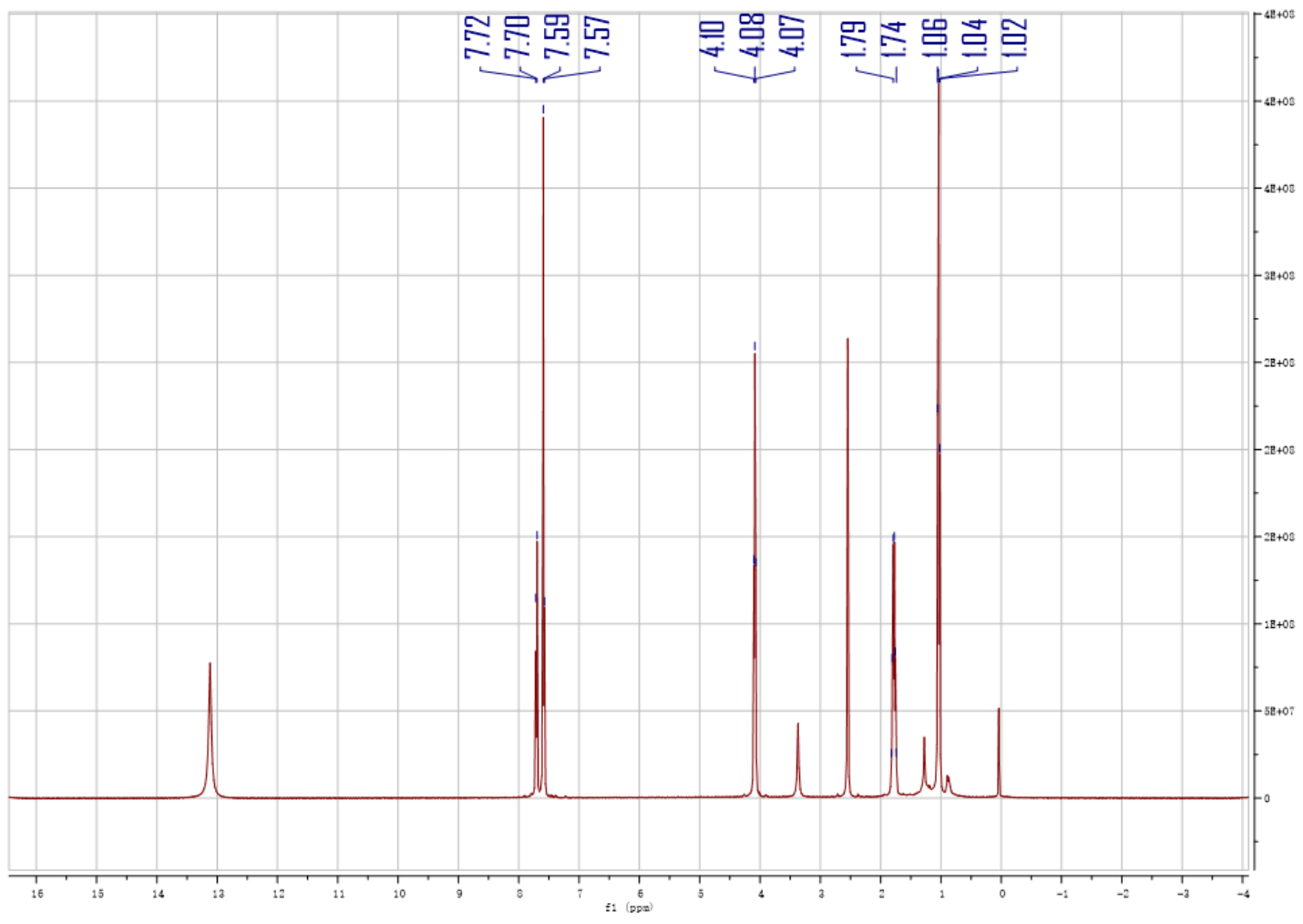

Figure S3 ${ }^{1} \mathrm{H}$ NMR(400MHz, DMSO) spectra of the linker of UiO-66-3 


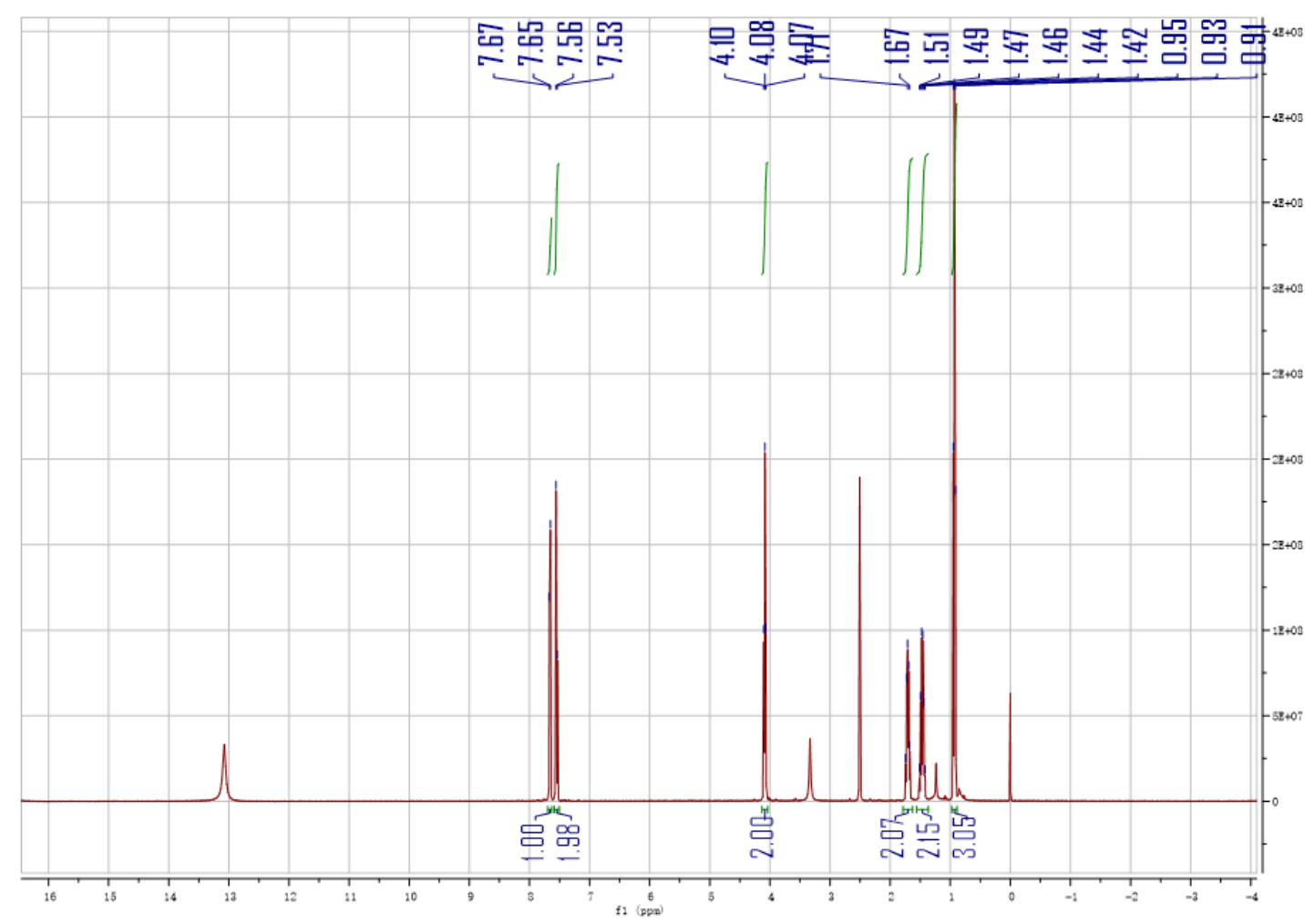

Figure S4 ${ }^{1} \mathrm{H}$ NMR(400MHz, DMSO) spectra of the linker of UiO-66-4 
Section S2 Characterization results of the adsorbents
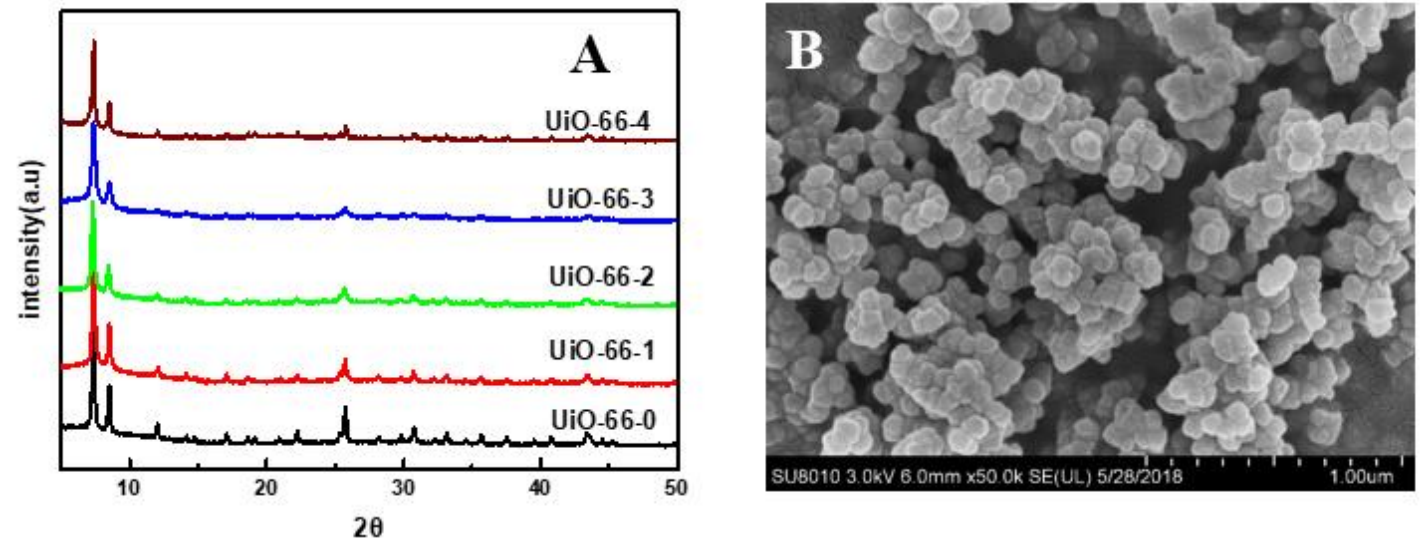

Figure S5 (A)The XRD patterns of five materials; (B) SEM micrograph of UiO-66-3

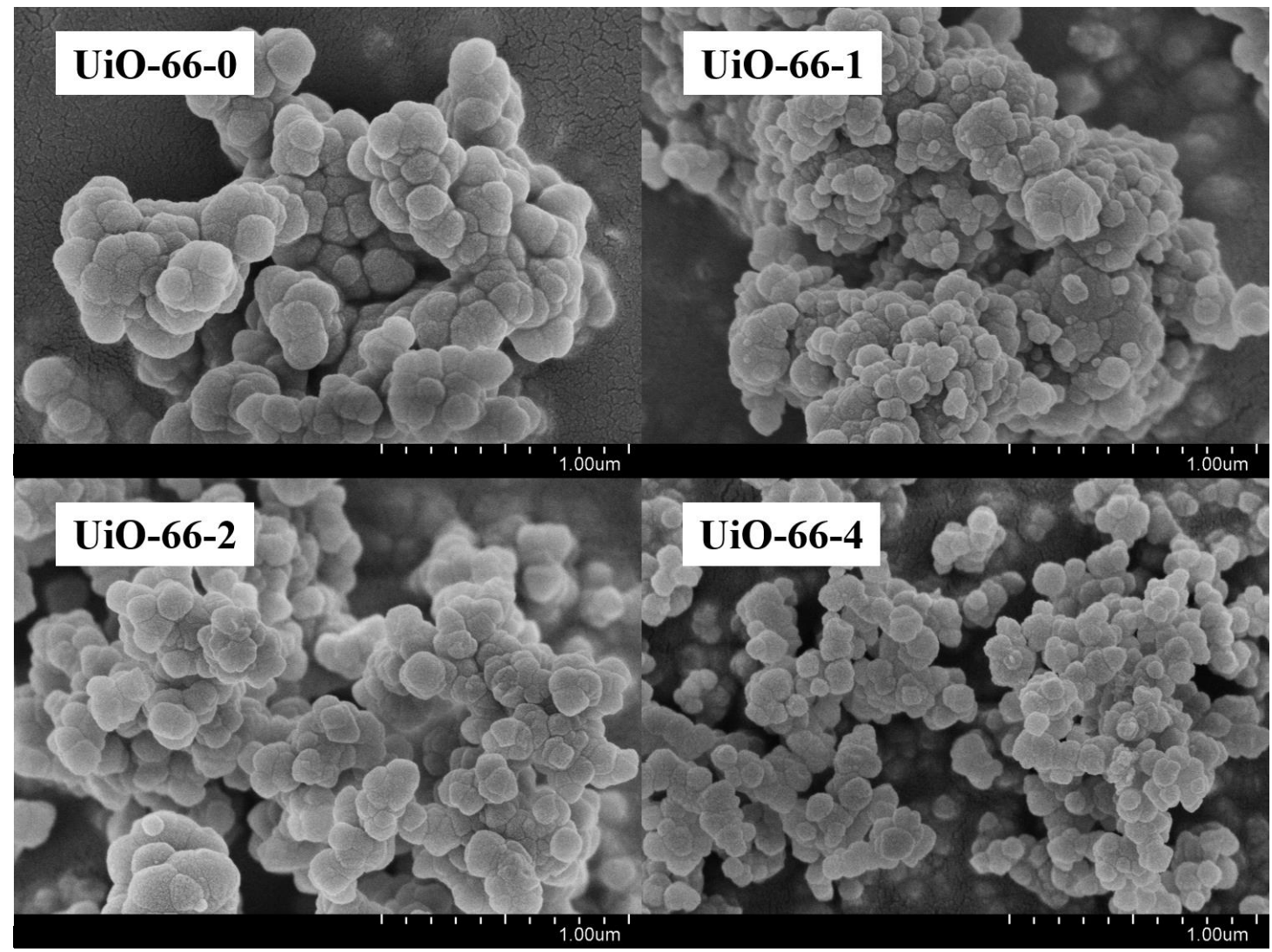

Figure S6 SEM micrograph of four other materials 

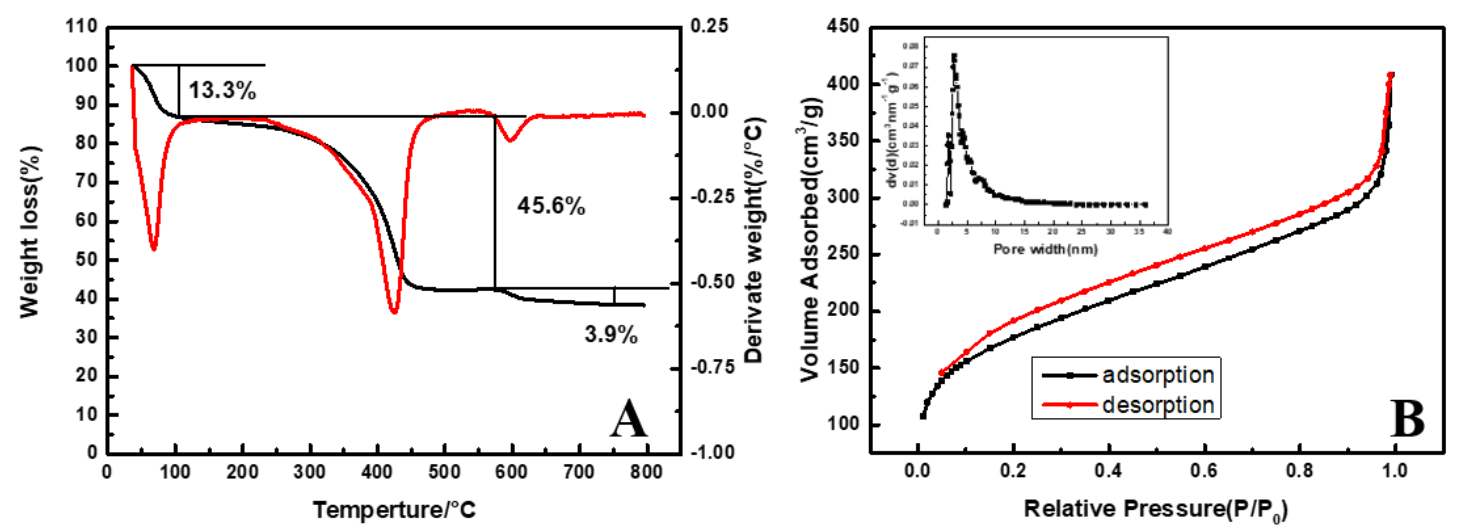

Figure S7 (A)TGA curve of UiO-66-3; (B) $\mathrm{N}_{2}$-adsorption isotherms of UiO-66-3

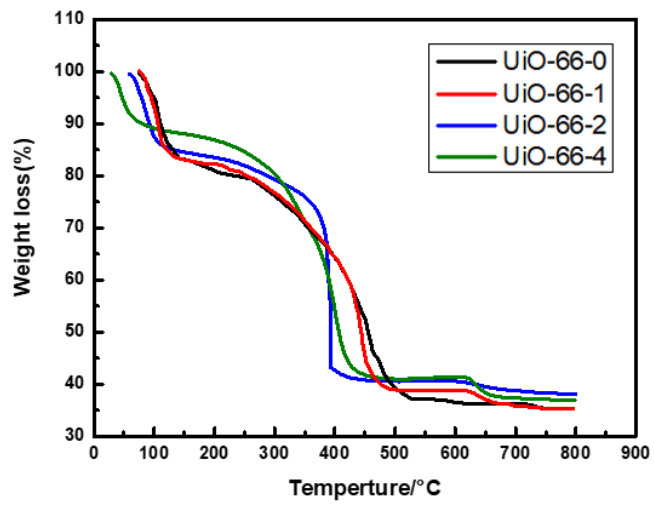

Figure S8 TGA curve of four other materials
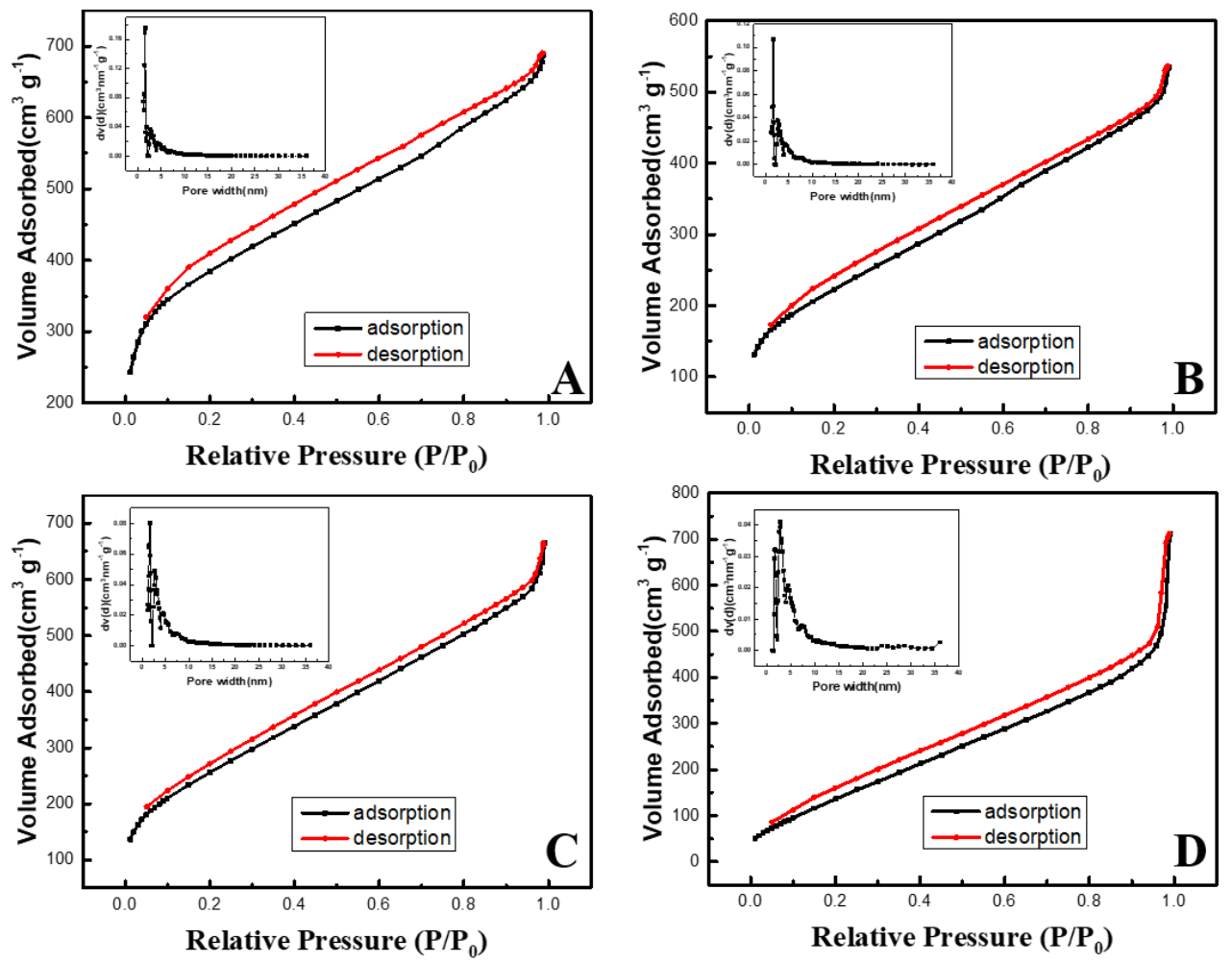

Figure S9 $\mathrm{N}_{2}$-adsorption isotherms of (A) UiO-66-0;(B)UiO-66-1; (C)UiO-66-2; (D)UiO- 
Section S3 Textual properties of five UiO-66 samples

Table S1 Textual properties of five UiO-66 samples

\begin{tabular}{lccc}
\hline & $S_{\text {BET }} /\left(\mathrm{m}^{2} \mathrm{~g}^{-1}\right)$ & $V_{\text {Tot }} /\left(\mathrm{cm}^{3} \mathrm{~g}^{-1}\right)$ & $D_{a v} /(\mathrm{nm})$ \\
\hline UiO-66-0 & 863 & 0.59 & 1.4 \\
UiO-66-1 & 808 & 0.83 & 1.6 \\
UiO-66-2 & 945 & 1.03 & 1.7 \\
UiO-66-3 & 1066 & 1.21 & 1.8 \\
UiO-66-4 & 600 & 1.10 & 1.7 \\
\hline
\end{tabular}


Section S4 Simulation of acetic acid adsorption on UiO-66-3

The Sorption Locate module was used for exploration of the possible adsorption sites of acetic acid on the UiO-66-3. During the simulation, the COMPASS force field was used at $298 \mathrm{~K}$, loaded two acetic acid molecules and method selected metropolis. 
Section S5 Kinetic curves of acetic acid adsorption

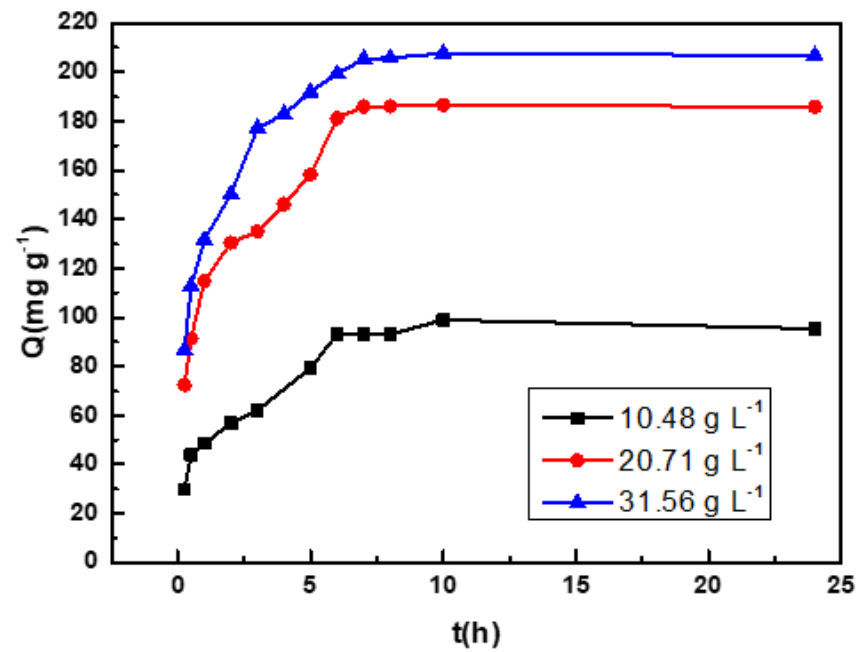

Figure S10 Kinetic curves of acetic acid adsorption 
Section S6 The Van't Hoff plot

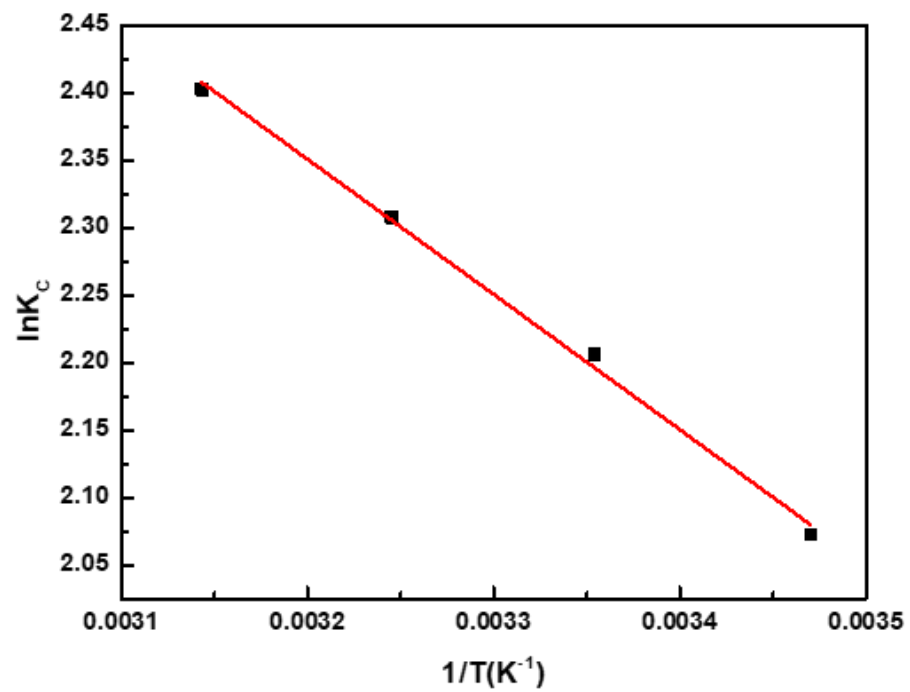

Figure S11 Van't Hoff plot 